\title{
Therapeutic hypothermia in asphyxiated neonates, using phase change material (Mira Cradle): experience from neonatal intensive care unit of tertiary care centre South India
}

\author{
Saraswat D. ${ }^{1}$, Aradhya G. ${ }^{2}$, Chaitali. R. ${ }^{3}$, Guruprasad G. ${ }^{4}$ \\ ${ }^{1}$ Dr. Devina Saraswat, Fellowship Resident, ${ }^{2}$ Dr. Gayathri Aradhya, Associate Professor, ${ }^{3}$ Dr. Chaitali R., Senior Resident, \\ ${ }^{4}$ Dr. G. Guruprasad, Head of Department; all authors are affiliated with Department of Neonatology, Bapuji Child Health \\ Institute, Davangere, Karnatka, India.
}

Corresponding Author: Dr. Devina Saraswat, Fellowship Resident, Department of Neonatology, Bapuji Child Health Institute, Davangere, Karnatka, India, E-mail: devina060788@gmail.com

\begin{abstract}
Introduction: Therapeutic hypothermia (TH) is now recommended for the treatment of neonates with Hypoxic-Ischemic Encephalopathy (HIE). This treatment protocol is applied in our department since June 2016. The aim of this study is to report our experience with whole body cooling in asphyxiated neonates admitted in a level 3, Bapuji NICU, Davangere. Patients and Methods: Prospective study of newborns admitted for HIE from July 2017 to July 2018 that is one year, in Neonatal Intensive Care Unit (NICU) of BCHI, Davangere. The results were reported as short term and long-term neurodevelopment assessment at 1-year age on a newborn group who received hypothermia. Results: Seventy-two cases of neonates with perinatal asphyxia were admitted in the unit. According to inclusion criteria 50 cases were eligible for the study. The arrival beyond six hours of life was the main cause accounting for not starting therapeutic cooling in birth asphyxia cases. Short come outcome measured in terms of requirement of anticonvulsants, cardiovascular instability, need of mechanical ventilation during stay was significantly reduced with therapeutic cooling. Long term outcome in term of neurodevelopment assessment at 1-year age found significant improvement overall in all domains. Conclusion: Our first experience with the controlled TH supports its beneficial effect in newborns with HIE. This treatment must be available in all the centers involved in the neonatal care.
\end{abstract}

Keyword: Birth asphyxia, Theraupetic cooling, Hypoxic-ischemic encephalopathy

\section{Introduction}

HIE in full term neonates is not unusual since it occurs among 1-3 newborns for 1000 live births [1]. The immediate and the long-term consequences can be serious. It is, indeed, responsible for a high mortality, globally, estimated at $23 \%$ of 4 million annual neonatal deaths [2,3] and source of neurologic disability estimated at $25 \%$ according to the most recent meta-analysis [4-6]. The pathophysiology of brain injury secondary to hypoxic ischemia (HI) is associated with 2 phases; primary and secondary energy failure based on characteristics of the cerebral energy state documented in both preclinical models and human infants [7-10].

Primary energy failure is characterized by reductions in cerebral blood flow and oxygen substrates. High-energy phosphorylated compounds such as ATP and phosphocreatine are reduced, and tissue acidosis is

Manuscript received: $28^{\text {th }}$ November 2019

Reviewed: $8^{\text {th }}$ December 2019

Author Corrected: $15^{\text {th }}$ December 2019

Accepted for Publication: $19^{\text {th }}$ December 2019 prominent. Primary energy failure is associated with an "excitotoxic-oxidative cascade" [11,12] with excessive stimulation of neurotransmitter receptors and membrane depolarization which mediates an increase in intracellular calcium and osmotic dysregulation [13]. Intracellular calcium activates neuronal nitric oxide synthase leading to release of the oxygen free radical nitric oxide which can disrupt mitochondrial respiration. Signals released from damaged mitochondria lead to apoptosis or programmed cell death as long as energy supplies persist, but exhaustion of these supplies leads to cell necrosis.

Apoptosis can also be triggered by activation of caspase enzymes. Resolution of hypoxia-ischemia within a specific time interval reverses the fall in high energy phosphorylated metabolites and intracellular $\mathrm{pH}$ and promotes recycling of neurotransmitters. If the injury is severe, the cascade of events results in a second interval of energy failure in the mitochondria, in which the brains energy supplies fall over a period of 24 hours [14]. 
Original Research Article

Secondary energy failure differs from primary energy failure in that the declines in phosphocreatine and ATP are not accompanied by brain acidosis [9]. The pathogenesis of secondary energy failure involves continuation of the excitotoxic-oxidation cascade, apoptosis, inflammation and altered growth factors, and protein synthesis [12]. The interval between primary and secondary energy failure represents a "latent phase" that corresponds to a "therapeutic window."

The duration of the window was noted to be approximately 6 hours in near-term fetal sheep treated with hypothermia initiated at varying intervals following timed HI injury $[15,16]$. Subsequent research has noted that cell death in the brain exposed to HI is delayed over several days to weeks after an injury and apoptosis and necrosis continue depending on the region and severity of the injury [12].

Six large randomized controlled trials (RCT) of hypothermia for neonatal HIE have been published, all enrolling infants $\geq 36$ weeks or $\geq 35$ weeks gestation, within the therapeutic window of 6 hours, with severe acidosis or need for resuscitation at birth, and the presence of moderate or severe encephalopathy. These trials have demonstrated that either head cooling $[17,18]$ or wholebody cooling $[19,20,21,22]$ decreases death or disability either in the entire cohort $[18,19,21,22]$ or within subgroups of infants $[17,20]$ at 18 to 24 months of age. Recent meta-analyses have demonstrated that hypothermia is effective and safe $[23,24]$. Neuroprotection by hypothermia has now been demonstrated by magnetic resonance imaging (MRI) of the brain [25,26].

The poor outcomes after hypoxic damage are virtually associated with the lack of any effective neuroprotective treatment following perinatal asphyxia, the management of which remained, until recently, supportive. The incidence of HIE is significantly higher in developing countries this may present heavy social and economic costs TH as whole body or selective head cooling has become a standard therapy for moderate-severe HIE to reduce neurological damage. Most recent meta-analyses documented the efficacy of $\mathrm{TH}$ in term infants with moderate to severe encephalopathy.

The safety of controlled hypothermia is now well established. No serious adverse events were reported to date by the randomized controlled studies [5]. Since the clinical benefits of $\mathrm{TH}$ are well established, it is considered the standard of care in many developed countries. This study aims to assess the feasibility of using this protocol in our tertiary care unit, to identify the problems encountered in its implementation, and to assess the outcome of these newborns.

\section{Population and Methods}

Population. This study was performed in a level 3 NICU BCHI, Davangere (Karnataka)

Type of Study and Data Collection. This is a prospective study. including neonates born in Bapuji Hospital, Davangere (inborn) and neonates referred from other institutes (outborn). Data were collected from patients files, analysing demographic parameters (gestational age, birth, and sex), perinatal-neonatal features (mode of delivery, acute intrapartum events, Apgar score at 1, 5, and 10 minutes, and the need of neonatal resuscitation), severity of HIE as assessed prior to cooling (Sarnat and Sarnat criteria), evolving information (hemorrhagic, infectious, renal complications, and death), and the result of the neurological examination during NICU stay.

For infants in the protocol group, the present had registered the time of cooling initiation after birth, the rectal temperature monitoring, the adverse effects, and interventions during cooling.

\section{Materials and Methods}

Survival and short-term outcome of children treated with therapeutic hypothermia for perinatal asphyxia have been followed up in a group of 50 newborn that were treated by that procedure at $\mathrm{BCHI}, \mathrm{NICU}$, Davangere.

Phase changing material (PCM) is one such low-cost technology used for cooling asphyxiated neonates. MiraCradle- Neonate Cooler is a PCM-based cooling device that has recently been developed and used in India.

\section{Inclusion criteria}

\section{Inborn}

1. Cord blood $\mathrm{Ph}<7 /$ base deficit $>12$

2. 5-Minute APGAR $<5$

3. Need for resuscitation $>10 \mathrm{~min}$

\section{Outborn}

1. History of not cried after birth

2. Bag \& Mask ventilation, bag \& Tube ventilation

3. APGAR@5 Minute $<5$

4. Moderate- severe encephalopathy acc to Sarnat \& Sarnat Staging

5. Presence of Seizure.

\section{Exclusion criteria}

1. Babies with major congenital, chromosomal anomaly

2. Gestational Age $<36$ weeks

3. Birth weight $<2000 \mathrm{~g}$

4. Inability to initiate cooling by 6 hours of age. 
The target temperature was $33.5 \pm 0.5 \mathrm{oC}$. TH was started within 6 hours after birth and continued for 72 hours, followed by slow rewarming over 10-12 hours at the rate of $0.2-0.5 \mathrm{oC}$ per hour. Core body temperature was monitored continuously using a rectal probe during the cooling and rewarming phase and for 12 hours after the rewarming was complete. The rectal probe was inserted to a depth of 2-3 $\mathrm{cm}$ and it was sterilized after use.

Mira Cradle-Neonate Cooler has a cradle made of nonconducting material, PCM blocks kept in the hollowed-out area and a conducting mattress above the PCM blocks, on which the baby is nursed. The PCM blocks are stored in the refrigerator $\left(2-8^{\circ} \mathrm{C}\right)$ and should be solid when taken for use. They were disinfected with surgical spirit.

Two types of PCM blocks were used, FS-29 (FS, form stable) with melting point of $29^{\circ} \mathrm{C}$ and FS-21 with melting point of $21^{\circ} \mathrm{C}$. During the induction phase, both FS-29 and FS-21 were used to decrease the baby's core temperature to the target range as quickly as possible. When the temperature reached $33.8^{\circ} \mathrm{C}$, the FS- 21 was removed and only FS-29 was used during the maintenance phase. The upper and lower alarm limits were set on the multiparamonitor at $33.8^{\circ} \mathrm{C}$ and $33.2^{\circ} \mathrm{C}$ respectively. If the baby's temperature reached $\geq 33.8^{\circ} \mathrm{C}$, FS-21 was added till the temperature came down to $33.5^{\circ} \mathrm{C}$. If the temperature reached $\leq 33.2^{\circ} \mathrm{C}$ (lower alarm limit), steps taken to increase the core temperature by switching on the radiant warmer. The radiant warmer was used in manual mode with an output of $10 \%$ to start with and adjusted in increments or decrements of $10 \%$ depending on the baby's temperature.

Continuous monitoring of vital parameters was done. The study infants had a central venous line. Blood counts, prothrombin time (PT) and activated partial thromboplastin time (aPTT), serum creatinine, serum electrolytes, and C-reactive protein (CRP) were monitored during cooling. All the other treatment modalities including ventilation, medications (antibiotics, anticon-vulsants and inotropes) and use of blood products were done as per the protocol of unit.

Statistical Analysis. The results were expressed as number and percentage.

\section{Results}

After the implementation of the protocol in this unit, 50 neonates among 72 hospitalized for neonatal asphyxia had the indication of TH and were included in the study. The remaining 22 were excluded from the study because they did not meet the TH inclusion criteria. The infants who were not cooled, mainly due to late referral after 6 hours of life.

Population characteristics- The observations were following, the average maternal age was 27 year 3 months, parity second, the most common pregnancy associate complication observed was PIH. Intrapartum observations of abnormal fetal heart rate followed by meconium stained liquor was seen. Prolonged second stage of labour followed by prolapsed cord and shoulder dystocia were associated with birth asphyxia cases (Table 1).

Table-1: Assessment of risk factors.

\begin{tabular}{|c|l|c|}
\hline 1$)$ & Maternal age (average) & $27.3 \mathrm{yr}$ \\
\hline 2$)$ & Parirty (average) & 2 \\
\hline 3$)$ & Pregnancy complications & 10 \\
\hline & GDM & 20 \\
\hline & PIH & 37 \\
\hline 4$)$ & Delivery complications & 22 \\
\hline & Abnormal foetal heart rate & 2 \\
\hline & Meconium stained liqour & 20 \\
\hline 5$)$ & Peripartum pathology & 2 \\
\hline & Prolapsed cord & \\
\hline & Prolonged 2nd stage labour & \\
\hline & Shoulder dystocia & \\
\hline
\end{tabular}

Amongst the admitted newborn there was no significant difference in sex of newborn, average birth weight was 3300 gms, APGAR score $<5$ at 5 min was in 21 newborn and APGAR $<5$ AT 10 min of life was in 11 babies. 11 babies required intubation at birth, whereas 7 needed chest compression along with intubation at the time of admission. 26 babies were in HIE stage 2 and 11 babies in HIE stage 3 according to Sarnat and Sarnat criteria (Table 2). 
Table-2: General characteristics of admitted new-borns.

\begin{tabular}{|l|c|}
\hline Male/Female & $27 / 23$ \\
\hline Birth weight (avg.) & $3300 \mathrm{~g}$ \\
\hline APGAR $<5 @ 5$ min & 21 \\
\hline APGAR $<5 @ 10$ MIN & 11 \\
\hline Intubation in delivery room & 11 \\
\hline Intubation only & 7 \\
\hline Intubation @ chest compression & 26 \\
\hline HIE Stage 2 & 11 \\
\hline HIE Stage 3 & 2 \\
\hline
\end{tabular}

Protocol assessment- Parents or caregivers of the asphyxiated neonates were informed about the important benefit of TH in the HIE. New-borns were admitted in the unit at $\mathbf{3 . 4} \pm \mathbf{1} \mathbf{h}$ of life. The average rectal temperature at admission was $\mathbf{3 3 . 4} \pm \mathbf{0 . 6}{ }^{\circ} \mathbf{C}$.

During NICU stay the babies included in the study had following complications - Most common complication was fluid resistant shock requiring inotropes, 11 babies required mono inotrope (dopamine), 5 babies required dual inotrope (dopamine, dobutamine). 14 babies needed ventilation. 17 babies were free of convulsions, rest needed anticonvulsants. 13 babies needed 1 AED, 17 required 2 AED and 3 babies required 3 AED's (Table 3).

Table-3: Immediate complications attributable to birth asphyxia.

\begin{tabular}{|l|c|}
\hline Shock & 11 \\
\hline Mono-inotrope & 5 \\
\hline Dual- inotrope & 3 \\
\hline Disseminated intravascular coagulation & 3 \\
\hline NEC & 1 \\
\hline Pneumothorax & 5 \\
\hline Acute Kidney Injury & 14 \\
\hline Ventilation & 3 \\
\hline Number of anticonvulsants used & 17 \\
\hline 3 AED'S & 13 \\
\hline 2 AED'S & 17 \\
\hline 1 AED'S & \\
\hline No Anticonvulsant & \\
\hline
\end{tabular}

Short term outcome: Average duration of hospitalisation was 12 days, almost all neonates tolerated the procedure well, 7 neonates died during stay (5 in HIE 3, \& 2 Neonates in HIE 2). Among them theraupetic cooling was stopped before completion in 4 babies who went against medical advice (Table 4 ).

Table-4: Short term outcome.

\begin{tabular}{|l|l|c|}
\hline 1$)$ & Average hospital stays (days) & 12 \\
\hline 2$)$ & Death & 7 \\
\hline 3$)$ & Normal neurological examination @ birth & 30 \\
\hline
\end{tabular}

Neurological examination at the time of discharge was done using Hammersmith new-born neurological examination [HNNE] 30 Babies had normal examination, whereas 10 babies observed to have some abnormality (Table 5). 
Original Research Article

Table-5: Neurological examination at the time of discharge using Hammersmith new-born neurological examination.

\begin{tabular}{|l|c|c|}
\hline Neurological examination at discharge & Normal & Abnormal \\
\hline Plantar grasp reflex at discharge & 30 & 10 \\
\hline Palmar grasp at discharge & 30 & 10 \\
\hline Muscle tone at discharge & 30 & 10 \\
\hline Moro's reflex at discharge & 30 & 10 \\
\hline
\end{tabular}

Long term outcome: The babies included in the study were followed up for the period of 12 months and repeat neurological examination revealed that 36 babies had normal neurological examination according to Hammersmith infant neurological examination, only 3 had psychomotor delay and 1 baby needed long term anticonvulsant (Table 6).

Table 6: Long term outcome-12 months.

\begin{tabular}{|l|c|}
\hline Normal neurological examination @ 12months & 36 \\
\hline Psychomotor delay & 3 \\
\hline Epilepsy & 1 \\
\hline
\end{tabular}

\section{Discussion}

The present study presented the experience with TH when preformed for the management of asphyxiated neonates with moderate and severe HIE, especially after the results of major randomized controlled studies that have shown a beneficial effect of controlled hypothermia on survival and long-term neurological outcome for newborns who suffered from HIE using either selective hypothermia $[11,12]$ or whole body cooling $[8,9,10]$. Our results are encouraging with respect to the feasibility and safety of total body cooling and the beneficial effect in terms of survival and neurodevelopmental outcome. Two principal methods of cooling exist: selective head cooling and the total body cooling. No superiority of either modality is supported by the existing evidence $[6,11,12]$.

The best neuroprotective effect is obtained if the treatment is started before 6 hours of life as shown in animal studies, where there is still a "therapeutic window" where secondary neuronal injury could be prevented or reduced by brain cooling $[27,28,29]$. In fact, cooling babies before $3^{\text {rd }}$ hour of age is even suggested by Thoresen et al. to obtain the optimal neuroprotective effect [30] and in the TOBY study, hypothermia was more effective in children treated during the first four hours after birth [30].

The average time for starting hypothermia was $3.3 \pm 1 \mathrm{~h}$ in this study. About $30 \%$ (22) of newborns referred in this center arrived too late, which explains the reason why they could not be included in study. This problem has already been discussed in other studies analyzing the feasibility of hypothermia in low income and middle income countries [25] in which the therapeutic time-window for administering beneficial cooling may be already passed, due to delayed hospital admissions, prolonged or obstructed labor, and lack of neonatal transport facilities.
It therefore seems necessary to improve the diffusion of this protocol within the perinatal network by promoting rapid transfer policy to level III centers of newborns with HIE. Starting the hypothermia protocol before $6 \mathrm{~h}$ of life assumes a rapid assessment of the severity of HIE and therefore early recognition of anoxic-ischemic nature. Close and repetitive clinical assessment (every 1-2 $\mathrm{h}$ during the first $6 \mathrm{~h}$ ) is required for these patients to determine the stage of HIE and if the HIE stage progresses from stage I to stage II therapeutic hypothermia should be started immediately. However, detailed neurological examination of an asphyxiated newborn according to criteria defined by Sarnat and Sarnat, originally during the first 48 hours of life [27], may be defective in some urgent assessment circumstances such as painful or sedated newborn.

Limitations of the present study- Amplitude EEG study is not being performed before starting cooling, only clinical assessment was the tool to include.

1) Due to delayed referral many babies could not be involved in study.

\section{Conclusion}

The machines that would help cool the newborns cost over Rs 15 lakh and most hospitals in India do not have them. Whereas the MiraCradle-Neonate Cooler, costs only Rs 1.6 lakh. And it does not need continuous electricity. Once it has been stored in a refrigerator for six to eight hours, it can be used for up to 72 hours without uninterrupted power. So, it appears to be a cost-effective measure which can reduce the progression of hypoxic damage and hence improve neurodevelopment outcome later. 
Original Research Article

\section{What the study adds to the existing knowledge?}

Implementation of theraupetic hypothermia using phase change material (mira cradle) has a definite role in reducing morbidity associated with birth asphyxia. And being a low-cost device, it can be easily used in resource poor settings with very low maintenance cost. Hence therapeutic cooling should become a standard of care in mild to moderate birth asphyxia cases.

\section{Author's contribution-}

Dr. Devina Saraswat: Prepared the manuscript

Dr. Gayathri Aradhya: Collected and analysed data

Dr. Chaitali R.: Collected and analysed data

Dr. G. Guruprasad: Concept of the study

Funding: No funding sources

Conflict of interest: None declared

Ethical Approval: This study was approved by the Institutional Ethics Committee

\section{References}

1. Graham EM, Ruis KA, Hartman AL, Northington FJ, Fox HE. A systematic review of the role of intrapartum hypoxia-ischemia in the causation of neonatal encephalopathy. Am J Obstet Gynecol. 2008; 199(6): 587-595. doi: 10. 1016/j.ajog.2008.06.094.

2. Lawn JE, Cousens S, Zupan J. 4 Million neonatal deaths: when? where? why? The Lancet. 2005;365 (9462): 891-900. doi:10.1016/S0140-6736(05).

3.Robertson CM, Perlman M. Follow-up of the term infant after hypoxic-ischemic encephalopathy. Paediatr Child Health. 2006;11(5):278-282.

4. Pin TW, Eldridge B, Galea MP. A review of developmental outcomes of term infants with post-asphyxia neonatal encephalopathy. Europe J Paediat Neurol.2009; 13(3):224-234.doi:10.1016/j.ejpn.2008.05. 001

5. Jacobs S, Hunt R, Tarnow W. Cooling for newborns with hypoxic ischaemic encephalopathy. Coch Database System Rev. 2013;(1):CD003311. doi:10.1002/14651858. CD 003311. pub3.

6. Tagin MA, Woolcott CG, Vincer MJ, Whyte RK, Stinson DA. Hypothermia for neonatal hypoxic ischemic encephalopathy: an updated systematic review and metaanalysis. Arch Pediatr Adol Med. 2012;166(6):558-566. doi:10.1001/archpediatrics.2001.1772.

7. Sarnat HB, Sarnat MS. Neonatal encephalopathy following fetal distress: a clinical and electroence- phalographic study. Arch Neurol. 1976; 33(10): 696-705. doi:10.1001/archneur. 1976.00500100030012.

8. Simbruner G, Mittal RA, Rohlmann F. Systemic Hypothermia after Neonatal Encephalopathy: outcomes of neo. nEURO. network RCT. Pediatr. 2010;126(4):e771e778. doi:10.1542/peds.2009-2441.

9. Shankaran S, Laptook AR, Ehrenkranz RA. Tyson JE, Mc Donald SA, et al Whole-body hypothermia for neonates with hypoxic-ischemic encephalopathy. New Eng J Med. 2005:353(15);1574-1584. doi: 10.1056/NEJM cps 050929 .

10. Eicher DJ, Wagner CL, Katikaneni LP. Moderate hypothermia in neonatal encephalopathy: efficacy outcomes. Pediatr Neurol. 2005;32(1):11-17. doi: 10. 1016 / j. pediatrneurol.2004.06.014.

11. Johnston MV, Trescher WH, Ishida A, Nakajima W. Neurobiology of hypoxic-ischemic injury in the developing brain. Pediatr Res.2001;49(6):735-741.doi: 10. 1203 / 00006450-200106000-00003.

12. Johnston MV, Fatemi A, Wilson MA Northington F. Treatment advances in neonatal neuroprotection and neurointensive care. Lancet Neurol. 2011;10(4):372-382. doi: 10.1016/S1474-4422(11)70016-3.

13. Cross JL, Meloni BP, Bakker AJ, Lee S, Knuckey NW. Modes of neuronal calcium entry and homeostasis following cerebral ischemia. Stroke Res Treat. 2010;2010. doi: http://dx.doi.org/10.4061/2010/316862.

14. Hagberg $H$, Mallard $C$, Rousset CI, Wang $X$. Apoptotic mechanisms in the immature brain: involvement of mitochondria. J Child Neurol. 2009;24(9):1141-1146.

15. Gunn AJ, Gunn TR, de Haan HH, Williams CE, Gluckman PD. Dramatic neuronal rescue with prolonged selective head cooling after ischemia in fetal lambs. J Clin Invest. 1997;99(2):248-256. doi: 10.1172/JCI1 19153.

16. Gunn AJ, Bennet L, Gunning MI, Gluckman PD, Gunn TR. Cerebral hypothermia is not neuroprotective when started after postischemic seizures in fetal sheep. Pediatr Res. 1999; 46(3):274-280. doi:10.1203/00006450199909000-00005.

17. Gluckman PD, Wyatt J, Azzopardi DV, Ballard R, Edwards AD, Ferriero DM, et al. Selective head cooling with mild systemic hypothermia after neonatal encephalopathy: multicenter randomized trial. Lancet. 2005;365 (9460): 663-670. doi: https://doi.org/10.1016/S0140-6736 (05) 17946-X. 
Original Research Article

18. Zhou WH, Cheng GQ, Shao XM, Liu XZ, Shan RB, Zhuang DY, et al. Selective head cooling with mild systemic hypothermia after neonatal hypoxic-ischemic encephalopathy: a multicenter randomized controlled trial in China. J Pediatr. 2010; 157(3):367-372. doi: 10.1016/j. jpeds. 2010.03.030. Epub 2010 May 20.

19. Shankaran S, Natarajan G, Chalak L, Pappas A, McDonald SA, Laptook AR. Hypothermia for neonatal hypoxic-ischemic encephalopathy: NICHD Neonatal Research Network contribution to the field. Semin Perinatol.2016;40(6):385-390.doi:10.1053/j.semperi.2016. 05.009. Epub 2016 Jun 23.

20. Azzopardi DV, Strohm B, Edwards AD, Dyet L, Halliday HL, Juszczak E, et al. Moderate hypothermia to treat perinatal asphyxia encephalopathy. N Engl J Med. 2009; 361(14):1349-1358. doi: 10.1056/NEJMoa0900854.

21. McAdams RM, Juul SE. Neonatal encephalopathy: update on therapeutic hypothermia and other novel therapeutics. Clinic Perinatol. 2016;43(3):485-500. doi: 10. 1016/j.clp.2016.04.007. Epub 2016 Jun 22.

22. Jacobs SE, Morley CJ, Inder TE, Stewart MJ, Smith $\mathrm{KR}$, McNamara PJ, et al. Whole-body hypothermia for term and near-term newborns with hypoxic-ischemic encephalopathy: a randomized controlled trial. Arch Pediatr Adolesc Med. 2011;165(8):692-700. doi: 10.1001/ archpediatrics.2011.43. Epub 2011 Apr 4.

23. Tagin MA, Woolcott CG, Vincer MJ, Whyte RK, Stinson DA. Hypothermia for neonatal hypoxic ischemic encephalopathy: an updated systematic review and metaanalysis. Arch Pediatr Adolesc Med. 2012;166(6):558566. doi: 10.1001/archpediatrics.2011.1772.

24. Edwards AD, Brocklehurst P, Gunn AJ, Halliday H, Juszczak E, Levene M, et al. Neurological outcomes at 18 months of age after moderate hypothermia for perinatal hypoxic ischemic encephalopathy: synthesis and metaanalysis of trial data. BMJ. 2010; 340:c363. doi: https: // doi.org/10.1136/bmj.c363.

25. Rutherford $\mathrm{M}$, Ramenghi LA, Edwards AD, Brocklehurst P, Halliday H, Levene M, et al. Assessment of brain tissue injury after moderate hypothermia in neonates with hypoxic-ischemic encephalopathy: a nested substudy of a randomized controlled trial. Lancet Neurol. 2010; 9(1):39-45. doi: 10.1016/S1474-4422(09)70295-9. Epub 2009 Nov 5.

26. Shankaran S, Barnes PD, Hintz SR, Laptook AR, Zaterka-Baxter KM, McDonald SA, et al. Brain Injury Following Trial of hypothermia for neonatal hypox-icischaemic encephalopathy. Arch Dis Child. 2012;97(6): F398-F404. doi:10.1136/archdischild-2011-301524.

27. Dixon G, Badawi N, Kurinczuk JJ, Keogh JM, Silburn SR, Zubrick SR, et al., Early developmental outcomes after newborn encephalopathy. Pediatr. 2002;109(1):2633. doi: 10.1542/peds.109.1.26.

28. Mullany LC. Neonatal hypothermia in low-resource settings. Seminars in Perinatol. 2010;34(6):426-433. doi: 10.1053/j.semperi.2010.09.007.

29. Thoresen M, Tooley J, Liu X, Jary S, Fleming P, Luyt $\mathrm{K}$, et al., Time is brain: starting therapeutic hypothermia within three hours after birth improves motor outcome in asphyxiated newborns.Neonatol.2013;104(3):228233. doi: $10.1159 / 000353948$.

30. Gunn AJ, Gunn TR, Gunning MI, Williams CE, Gluckman PD. Neuroprotection with prolonged head cooling started before postischemic seizures in fetal sheep. Pediatr. 1998;102(5):1098-1106. doi: https://doi.org/10. 1542 / peds.102.5.1098.

\section{How to cite this article?}

Saraswat D, Aradhya G, Chaitali. R, Guruprasad G. Therapeutic hypothermia in asphyxiated neonates, using phase change material (Mira Cradle): experience from neonatal intensive care unit of tertiary care centre South India. Int J Pediatr Res.2019; 6(12):606-612.doi:10.17511/ijpr.2019.i12.04 